\title{
O CÔMICO E O FANTÁSTICO EM “O NARIZ”, DE AKUTAGAWA
}

\author{
THE COMIC AND THE FANTASTIC IN "THE NOSE", BY \\ AKUTAGAWA
}

\author{
Fábio Dobashi FURUZATO*
}

\begin{abstract}
Resumo: Neste trabalho, analisamos o conto "O nariz", do escritor japonês Ryûnosuke Akutagawa (1892-1927), buscando examinar o modo como se combinam o cômico e o fantástico na narrativa em questão. Adaptado do Konjaku Monogatari, coletânea de contos populares do período Heian (794-1185), este conto também recebeu influência do célebre trabalho homônimo de Nicolai Gógol (1809-1852), conforme observa o crítico coreano Beongcheon Yu (1976). De acordo com David Roas (2014), "O nariz", de Gógol, é um exemplo de grotesco, pois, neste conto, o humor anularia o efeito fantástico. Isso porque, para o teórico espanhol, o fantástico se constrói a partir de um acontecimento dentro da narrativa que leva o leitor a questionar a sua própria concepção de realidade. Assim, para que se dê o efeito fantástico, é necessária uma boa dose de realismo na narrativa, combinada evidentemente com algo sobrenatural. Mas, diante dos acontecimentos completamente absurdos relatados na história de Gógol, a inquietação característica do fantástico perderia sua força, dando lugar ao humor. Essa combinação entre sobrenatural e humor é considerada, por Roas, como grotesca. Investigamos, portanto, se algo semelhante acontece também em "O nariz", de Akutagawa. Por fim, para além da análise desta narrativa específica, nosso trabalho nos leva a compreender que o fantástico como "modo", por ser mais abrangente e flexível, é um conceito mais produtivo do que a ideia do fantástico como um "gênero".
\end{abstract}

Palavras-chave: Ryûnosuke Akutagawa (1892-1927). O nariz. Fantástico. Humor. Grotesco.

\begin{abstract}
This paper presents an analysis of the short story "The nose", by the Japanese writer Ryûnosuke Akutagawa (1892-1927), seeking to examine how comic and fantastic are combined in the narrative. Adapted from Konjaku Monogatari, a collection of folk tales from the Heian period (7941185), this short story was also influenced by the famous work of the same name by Nicolai Gógol (1809-1852), as noted by the Korean critic Beongcheon Yu (1976). According to David Roas (2014), "The nose", by Gógol, is an example of the grotesque, because, in this story, humor would nullify the fantastic effect. For Roas, this is because, the fantastic is built from an event within the narrative that leads the reader to question his/her own conception of reality. So, for the fantastic effect to take place, a good deal of realism in the narrative is needed, evidently combined with something supernatural. But, in view of the completely absurd events reported in the story of Gógol, the characteristic anxiety of the fantastic would lose its strength, yielding to humor. This combination of the supernatural and humor is considered by Roas to be grotesque. It is worth investigating, therefore, if something similar also happens in Akutagawa's "The nose". In addition to analyzing this specific narrative, this paper leads us to understand that the fantastic as a "mode", for being more comprehensive and flexible, is a more productive concept than the idea of the fantastic as a "genre".
\end{abstract}

Keywords: Ryûnosuke Akutagawa (1892-1927). The nose. Fantastic. Humor. Grotesque.

\footnotetext{
* Doutor em Teoria e História Literária pela Universidade Estadual de Campinas. Professor da Universidade Estadual de Mato Grosso do Sul (UEMS). E-mail: fabiodf71 @yahoo.com.br ORCID ID: https://orcid.org/0000$\underline{0001-5172-404 X}$
} 


\section{"Hana", de Akutagawa}

Este trabalho se propõe a investigar a maneira como se combinam o humor e o fantástico, no conto "O nariz", do escritor japonês Ryûnosuke Akutagawa (1892-1927). Nessa análise, também vamos nos basear no conceito de grotesco, que, para David Roas (2014), é justamente a combinação do fantástico com o humorístico. Por fim, procuraremos relacionar os resultados de nossa investigação com a defesa de que a concepção do fantástico como "modo", e não como "gênero", acaba sendo mais produtiva.

Tendo vivido apenas 35 anos, Akutagawa - mais conhecido, entre nós, pela autoria de “Rashômon", que inspirou o cineasta Akira Kurosawa (1910-1998), em seu filme homônimo chegou a escrever mais de cento e cinquenta histórias curtas. E, mesmo sendo essencialmente um contista, também se dedicou a outros gêneros literários, como a poesia, o ensaio e as memórias, além de traduzir obras de escritores ocidentais para o japonês. Seu gosto pela literatura ocidental incluía muitos grandes autores europeus, como Maupassant, Ibsen, Anatole France, Baudelaire, Dostoievski, Tolstoi, Strindberg, Poe e - cabe destacar aqui - Nicolai Gógol.

Esse destaque é importante, porque, de acordo com o crítico coreano Beongcheon Yu (1976), o conto “O nariz", de Akutagawa, baseado no Konjaku Monogatari, coletânea de contos populares do período Heian (794-1185), também recebeu influência do célebre trabalho homônimo de Gógol. E, para o teórico espanhol David Roas (2014), “O nariz”, do escritor russo, é um exemplo de grotesco, ou seja, um caso em que o humor anula o efeito fantástico. Diante disso, perguntamo-nos, portanto, se o mesmo ocorre no conto de Akutagawa.

Publicado pela primeira vez em 1916, o conto em questão - "Hana”, em japonês - relata as desventuras de um bonzo, chamado Zenchi Naigu, cujo nariz era tão grande e grosso que parecia uma linguiça pendurada no meio do seu rosto. Essa característica lhe dificultava muito as questões práticas do dia-a-dia, como se alimentar, por exemplo, pois seu membro entrava dentro da tigela de sopa. Assim, toda vez que o bonzo ia tomar sua refeição, precisava da ajuda de um discípulo, que escorava o seu nariz com uma tabuinha.

E, pior do que essas dificuldades práticas, era o seu problema de autoestima, que o impedia de se dedicar àquilo que deveria ser o objetivo principal na vida de um monge, ou seja, o desenvolvimento espiritual.

Certo dia, porém, um discípulo seu retornou de viagem, tendo recebido de um médico chinês as orientações acerca de um método de diminuição de nariz. Após fingir certa relutância, para parecer que não se importava tanto com a própria aparência, o bonzo se submeteu ao tal método, que consistia em mergulhar o nariz em água fervente e, em seguida, tê-lo pisoteado pelo discípulo. Feito isso, o nariz de Naigu expeliu uma espécie de sebo pelos poros, que foi 
sendo lentamente extraído com uma pinça. Por fim, o nariz foi cozido novamente e, por incrível que pareça, o método funcionou.

Para a surpresa do bonzo, porém, ao invés de essa mudança levar a uma diminuição da zombaria de que era alvo, o efeito foi justamente o contrário. Se, antes, as pessoas riam discretamente de seu nariz avantajado, depois da diminuição passaram a rir de modo escancarado. E isso podia ser observado na atitude de todos, desde as pessoas mais elevadas na hierarquia social, até os serviçais mais humildes, que fingiam respeitá-lo quando ele lhes dirigia a palavra, mas riam de Naigu logo que ele lhes virava as costas.

Diante dessa mudança na reação alheia, o bonzo inicialmente ficou bastante intrigado, pois não encontrava explicação para isso, uma vez que a nova aparência do nariz era certamente mais normal. Desconhecendo a razão para o aumento na intensidade dos risos, ele ficou profundamente magoado e, com o passar dos dias, o seu humor foi ficando cada vez pior. Naigu chegou a sentir saudades de quando ostentava um nariz de linguiça no meio do rosto e revoltouse por ter tomado aquela decisão de diminuí-lo.

O temperamento do monge estava de tal forma alterado que um dos seus discípulos começou a se queixar de que ele não transmitia mais os ensinamentos de Buda. E assim os dias foram passando, até que, numa determinada noite, Naigu sentiu uma espécie de febre apenas no nariz.

Na manhã seguinte, logo ao despertar, o bonzo inspirou profundamente o ar e sentiu uma sensação familiar que quase já havia esquecido. Então, apalpou o rosto e sentiu que o seu nariz de linguiça estava de volta, com seus quinze centímetros e a ponta que chegava até embaixo do queixo. Sentiu-se radiante, como daquela vez em que conseguira encurtá-lo: ““Ah! Agora com certeza ninguém rirá!', segredou Naigu em seu íntimo, passeando o seu comprido nariz ao despertar do dia, sob o vento de outono". (AKUTAGAWA, 2003, p. 33).

\section{O grotesco e o fantástico}

Antes de nos deter na análise propriamente dita do conto escolhido, vamos apresentar brevemente os principais conceitos teóricos escolhidos como ponto de partida neste trabalho.

O termo "grotesco", como sabemos, é de origem italiana, sendo derivado de "gruta". E o seu surgimento está relacionado com um tipo de ornamentação encontrada, no final do século $\mathrm{XV}$, em escavações feitas primeiramente em Roma e depois em toda a Itália. Mas, como observa Wolfgang Kayser (1986), o fenômeno estético é mais antigo do que o termo, sendo que a manifestação do grotesco tem ampla abrangência, desde a Antiguidade até os nossos dias, compreendendo também as mais variadas culturas, tanto do Ocidente, quanto do Oriente. 
Essa amplitude temporal e geográfica dificulta muito uma definição do grotesco, pois é preciso levar em conta não apenas a materialidade da obra, mas também o seu contexto de produção e recepção. Assim, uma determinada manifestação artística que, para nós, pode parecer grotesca, talvez não o seja no seu contexto cultural específico.

De qualquer forma, segundo Kayser, ainda seria possível descrever uma estrutura geral do grotesco. Uma de suas características, por exemplo, é a mistura de domínios, como ocorre nas ornamentações que deram origem ao nome, compostas por seres formados pela estranha combinação de elementos humanos e vegetais. E o teórico alemão amplia os exemplos, mencionando a mistura do animado com o inanimado, do animal com o humano, de diferentes animais entre si, de seres vivos com máquinas.

A mistura de domínios resulta em uma desorientação por parte do espectador. Por isso, o grotesco também se relaciona com um mundo tornado estranho, em que o conhecido adquire um aspecto sinistro e ameaçador. E, como essa desorientação também representa uma ameaça à razão, não por acaso, o grotesco se aproxima do mundo do sonho e do inconsciente.

O caráter absurdo do grotesco pode expressar ainda uma falta de sentido sobre a própria existência, uma espécie de "olhar frio sobre a azáfama na terra, que é vista como um jogo de títeres, vazio, sem sentido, um teatro de marionetes, caricato" (KAYSER, 1986, p. 160).

Dentre as manifestações grotescas, haveria duas grandes tendências, que Kayser denomina de "grotesco fantástico" e "grotesco satírico", sendo que a segunda nos aproxima mais do nosso tema, ou seja, da relação entre o humor e o fantástico.

Ainda segundo ele, o ridículo faz parte do grotesco quando "o riso provém, desde logo, das antecâmaras cômicas, caricaturescas. Já misturado com a amargura, assume, na passagem para o grotesco, traços da gargalhada zombeteira, cínica e, finalmente, satânica" (KAYSER, 1986, p. 160).

Em seus aspectos mais terríveis, esse riso paradoxal configura uma espécie de "jogo com o absurdo":

\footnotetext{
A pergunta acerca do riso no grotesco tropeça no mais difícil complexo parcial de todo este fenômeno. Não é possível oferecer uma resposta unívoca; com efeito, já no conteúdo, encontramos como motivo o riso involuntário e abridor de abismos: o narrador das Vigílias de Bonaventura sentia necessidade de rir nas igrejas e as personagens de E. T. A. Hoffmann prorrompiam em risadas, em momentos em que não estavam de modo algum dispostas a rir. (KAYSER, 1986, p. 161)
} 
Já o teórico espanhol David Roas (2014) entende o grotesco como uma combinação entre o sobrenatural e o riso. Para ele, é importante diferenciar o fantástico do grotesco, pois o humor anularia a inquietação necessária ao fantástico.

Isso porque, segundo Roas, o efeito fantástico consiste em uma ameaça sentida pelo leitor sobre a sua própria concepção de realidade. A narrativa fantástica pressupõe um mundo realista, no qual irrompe algum fenômeno sobrenatural, que desestabiliza as leis de funcionamento desse mundo ficcional. Mas, uma vez que este mundo da ficção é semelhante ao real, o leitor sente que, se o sobrenatural é possível no interior da narrativa, também o seria em sua própria realidade.

É por isso, por exemplo, que, após a leitura de um conto como “O Horla”, de Maupassant, podemos sentir medo de dormir sozinhos em casa, pois a narrativa nos envolve de tal forma que somos convencidos da possibilidade de ocorrerem acontecimentos sobrenaturais em nossa própria realidade, como aqueles vividos pelo protagonista.

Já no caso do grotesco, o humor gera um distanciamento emocional, que anula a possibilidade do fantástico. Em um conto como "O nariz", de Gógol, por exemplo, o absurdo dos acontecimentos é tão exagerado que o leitor reage como se estivesse diante de uma caricatura, uma distorção da realidade.

Assim, quando o funcionário público Kovaliov acorda sem o nariz e, em seguida, depara-se com o próprio membro, vestido como "conselheiro de estado", ou seja, exercendo uma função superior à dele na hierarquia do funcionalismo público, diante de tais disparates na história narrada, o leitor não sente medo de perder o próprio nariz, mas dá risada. Isso porque a verossimilhança é quebrada e, como dissemos, também a identificação emocional entre o leitor e o protagonista.

David Roas considera ainda que, no grotesco, essa combinação entre o sobrenatural que ele associa com o terrível - e o humor pode pender mais para um lado ou mais para o outro, em cada narrativa ou manifestação artística específica. Enquanto Wolfgang Kayser teria dado maior destaque para o grotesco terrível, por se concentrar mais no período do Romantismo; Mikhail Bakhtin teria dado maior destaque para o grotesco humorístico ou satírico, em seu célebre estudo A cultura popular na Idade Média e no Renascimento.

A discussão mais aprofundada sobre todas essas categorias estéticas (fantástico, grotesco, humorístico), em seus diversos contextos culturais, foge aos limites do nosso trabalho. Mas, nessa breve explanação, podemos perceber que David Roas concebe o grotesco apenas a partir de uma de suas características, ou seja, da combinação entre o sobrenatural e o humorístico. Além disso, para Roas, o sobrenatural necessário ao fantástico está relacionado 
com a sensação de medo. E não por acaso, o teórico espanhol às vezes utiliza o termo terrível, como equivalente a sobrenatural, em suas observações sobre o grotesco.

Feitas essas considerações, passemos à análise propriamente dita.

\section{O fantástico e o grotesco em "Hana"}

A primeira coisa que devemos nos perguntar, em nossa análise do conto "O nariz", de Akutagawa, é sobre o caráter sobrenatural ou não dos acontecimentos centrais dessa história. Isso porque, para a maioria dos teóricos do fantástico, o sobrenatural é um elemento essencial para essa categoria narrativa.

Vejamos então como é descrito o nariz de Naigu, uma vez que o conflito narrativo tem origem nessa caracterização:

\footnotetext{
Em se tratando do nariz de Zenchi Naigu, não há pessoa em Ikeno’o que não o conheça. Tem mais ou menos quinze centímetros, começa acima do lábio superior e termina abaixo do queixo. Seu formato é constante da base à extremidade, sem alteração na grossura. É como uma grande linguiça - uma grande linguiça pendurada no meio do seu rosto. (AKUTAGAWA, 2003, p. 25).
}

Ora, uma coisa que não se pode negar é o exagero. Em primeiro lugar, pela fama que o nariz desperta; em segundo, pelo tamanho extraordinário, que ultrapassa o queixo; e, em terceiro, pelo formato completamente incomum.

Esse exagero é relevante, pois, como observa Todorov: "O sobrenatural pode por vezes ter sua origem na imagem figurada, ser o seu último grau; como as imensas serpentes ou os pássaros na narrativa de Sinbad: deslizamos então do hiperbólico ao fantástico" (TODOROV, 2003, p. 85).

A questão agora é saber qual o limite entre o natural e o sobrenatural, levando em conta esse grau de exagero. Em outras palavras, que tamanho precisa ter um nariz para que ele ultrapasse as leis da natureza?

Pois bem, o fato de o nariz de Naigu entrar na tigela de sopa, quando ele se alimenta, é algo que vai contra a lei da evolução das espécies. Por outro lado, não se pode afirmar que Naigu seja monstruoso, a ponto de causar medo nos demais personagens ou no leitor, por causa do tamanho de seu nariz. Assim, o caráter extraordinário desse fenômeno parece estar situado justamente no limite entre o natural e o sobrenatural. E o mesmo ocorre nos outros dois acontecimentos crucias da história, ou seja, a diminuição do nariz e a volta dele ao seu tamanho original. 
A diminuição, como foi dito, ocorreu a partir da aplicação de um método ensinado por um médico chinês a um discípulo de Naigu. Independentemente do caráter ridículo desse método, o fato é que, na história, ele funciona, como vimos no trecho citado acima: "o nariz encolhera, seu excesso fora levado pelo vento!” (AKUTAGAWA, 2003, p. 30).

E cabe destacar aqui a expressão "levado pelo vento!", caracterizando o modo repentino e admirável como se deu a diminuição.

A volta ao tamanho natural também se dá repentinamente, mas, nesse caso, sem que haja nenhum método e literalmente da noite para o dia: "O monge atinou que, no espaço de uma noite, seu nariz encompridara, voltando à forma original” (AKUTAGAWA, 2003, p. 33).

Assim, se a diminuição se tornou possível a partir de um método improvável, a volta ao tamanho anterior obedece à mesma lógica ou falta de lógica. E, enfim, tais acontecimentos também se situam no limite entre o natural e o sobrenatural.

Além disso, outro aspecto importante é a reação das personagens diante do ocorrido. Isso porque, para alguns críticos, como Todorov, o fantástico se caracteriza pela hesitação entre duas possibilidades de interpretação, diante de algo aparentemente sobrenatural, num mundo natural. E esta hesitação, que se dá na interpretação de um leitor virtual, costuma estar representada na atitude dos personagens e do narrador, pois a tendência é de que o leitor se identifique com essas instâncias narrativas.

Quanto a esse aspecto, o conto "O nariz", de Akutagawa, não se caracteriza como fantástico, uma vez que o conflito não gira em torno da hesitação formulada por Todorov. Em nenhum momento, nenhum personagem se pergunta se a existência de um nariz como o de Naigu é possível ou não e nem se questiona sobre o fato de ele ter ou não conseguido diminuir o nariz, nem de tê-lo aumentado novamente. E o próprio narrador também não propõe essas questões ao leitor.

O conflito central da narrativa gira em torno do incômodo que Naigu sente, diante da reação das pessoas ao tamanho do seu nariz. Sendo assim, podemos dizer que este conto de Akutagawa não é fantástico, conforme o conceito de Todorov; assim como também não o é, a partir da formulação teórica de Roas, uma vez que não representa uma ameaça à concepção que o leitor tem de sua própria realidade.

Por outro lado, o fato de o mundo descrito no conto ser realista e de, nesse mundo, ocorrerem acontecimentos que estão no limite entre o natural e o sobrenatural, isso faz com que a narrativa se aproxime de algum modo do fantástico.

Não por acaso, a coletânea de narrativas em que se encontra a versão do texto que analisamos denomina-se Contos fantásticos, de Ryûnosuke Akutagawa. E também há algo 
próximo do grotesco nesse nariz que, logo de início, é comparado a uma linguiça, sendo que, no decorrer da narrativa, a expressão "nariz de linguiça” é retomada várias vezes.

Já dissemos que o grotesco se constitui pela mistura de domínios, como no caso das gravuras encontradas nas grutas italianas, que eram compostas por elementos humanos e vegetais, ou ainda, como se vê abaixo, na famosa obra Vertumnus (1591), de Giuseppe Arcimboldo (1527-1593):

Figura 1 - Vertumnus (1591)

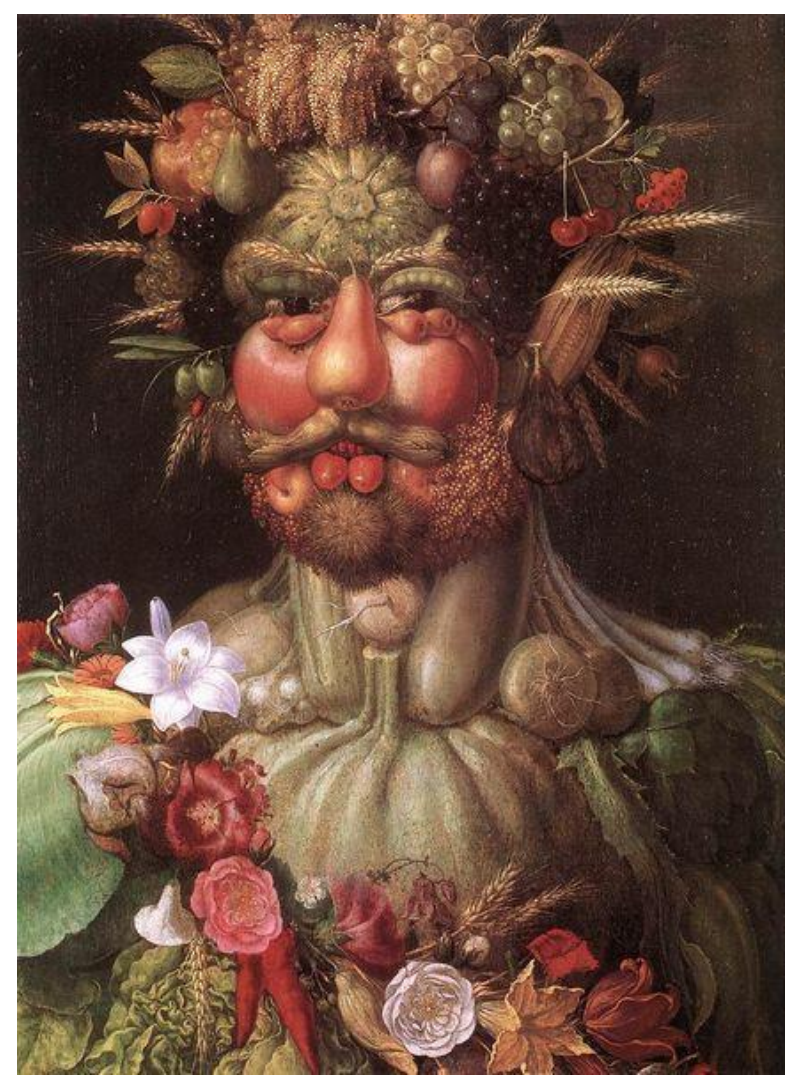

Fonte: http://materialartes.pbworks.com/

É claro que esta é apenas uma das características do grotesco, conforme a definição de Kayser. E também não é difícil perceber que o conto de Akutagawa se aproxima muito mais do grotesco satírico do que do terrível, pois não tem nada de ameaçador ou sinistro.

Pois bem, passemos agora a uma observação do escritor veterano Sôseki Natsume (1867-1916) a respeito deste conto do então autor estreante Akutagawa: "Eu achei a sua peça muito interessante. Sóbria e séria, sem tentar ser divertida, ela exala humor, um claro sinal de um gosto refinado". (SÔSEKI apud YU, 1976, p. 29 - tradução nossa) ${ }^{1}$.

\footnotetext{
${ }^{1}$ No original: "I found your piece very interesting. Sober and serious without trying to be funny, it exudes humor, a sure sign of refined taste."
} 
Ora, a presença do humor é inegável na narrativa que analisamos, mas, a esta altura, as diferenças entre ela e a obra homônima de Gógol já ficam mais claras. Enquanto o insólito no conto japonês se situa no limite entre o natural e o sobrenatural; no conto russo, isso é extremamente mais exagerado, aproximando-se muito mais do grotesco caracterizado por Roas, ou seja, de "uma situação que transcende toda verossimilhança e que vai além de qualquer sentido. A única coisa que interessa é a sua deformação" (ROAS, 2014, p. 119).

Mas como seria este tipo de humor que Sôseki Natsume procura caracterizar, considerando-o como "sinal de gosto refinado"?

\title{
O humorístico em "Hana"
}

De início, o humor presente no conto de Akutagawa tem alguma semelhança com o da comédia clássica:

\begin{abstract}
A comédia, como dissemos, é imitação de pessoas inferiores; não, porém, com relação a todo vício, mas sim por ser o cômico uma espécie do feio. A comicidade, com efeito, é um defeito e uma feiura, sem dor nem destruição; um exemplo óbvio é a máscara cômica, feia e contorcida, mas sem expressão de dor. (ARISTÓTELES, 1995, p. 234).
\end{abstract}

Nesse sentido, Naigu seria um personagem cômico, por apresentar um defeito, que o marca fisicamente, mas que corresponde a uma falha em seu caráter: a vaidade ou o fato de se preocupar mais com a autoestima do que com a espiritualidade.

Na comédia clássica, porém, o protagonista tende a ser punido no desfecho, para que o caso sirva de exemplo ao público, de tal modo que todos aqueles que tenham o mesmo defeito se identifiquem e se corrijam. E o riso, do qual o personagem é alvo, também é uma punição para o público que se identifica com o seu defeito, havendo, portanto, um claro sentido moralizante na história, o célebre: "Ridendo castigat mores"2.

Mas, no caso desta narrativa de Akutagawa, o sentido não parece tão claro assim, uma vez que o protagonista, no desfecho, fica satisfeito com a volta ao seu estado anterior, do ponto de vista físico. E, mais ainda, quanto ao caráter, continua se preocupando com a reação alheia: ““Ah! Agora com certeza ninguém mais rirá!', segredou Naigu em seu íntimo, passeando seu comprido nariz ao despertar do dia, sob o vento de outono" (AKUTAGAWA, 2003, p. 33).

Outra característica, na comédia clássica, é a oposição entre o protagonista e os demais personagens, que representam uma virtude, uma espécie de equilíbrio quanto àquele aspecto da

\footnotetext{
2 "Rindo moralizam-se os costumes". Para uma visão introdutória sobre a comédia, recomendamos a leitura do estudo de Vilma Arêas: Iniciação à comédia.
} 
personalidade defeituosa. E isso não ocorre no conto de Akutagawa, pois, se o defeito de Naigu é ser exageradamente preocupado com a própria imagem, os demais personagens deveriam ser desapegados com relação a isso.

No entanto, no momento em que Naigu fica mais intrigado com a reação das pessoas diante da diminuição de seu nariz, ou seja, diante do desaparecimento daquilo que ele acreditava ser a causa do seu sofrimento, a narrativa apresenta a seguinte reflexão:

No íntimo de todas as pessoas existem dois sentimentos que se contradizem. Não há
quem não sinta piedade da desgraça alheia, isso é claro. Porém, se o outro consegue
de algum modo superar a desdita, nos sentimos insatisfeitos, sem saber muito bem por
quê. Exagerando um pouco, podemos afirmar que desejamos que o outro se afunde
novamente e passe pelos mesmos infortúnios. Chegamos até a nutrir certo sentimento
de hostilidade em relação ao outro. Naigu, desconhecendo o motivo das risadas,
sentia-se muito magoado. De verdade. E essa mágoa nasceu ao perceber, na conduta
dos habitantes de Ikeno'o, aquele egoísmo característico dos espectadores da
desventura alheia. (AKUTAGAWA, 2003, p. 32).

Assim, em pleno conflito, o texto apresenta um defeito de caráter na natureza humana tão ou mais grave do que aquele do seu protagonista. Esta reflexão, na voz do narrador, pode ser interpretada também como um discurso indireto livre, ou seja, como um pensamento do próprio Naigu, projetado na voz narrativa.

De qualquer modo, o egoísmo que se constata nos habitantes de Ikeno’o não desperta a compaixão do bonzo. Do contrário, seu humor se deteriora e sua atitude se torna agressiva, chegando ao ponto máximo quando ele bate num jovem auxiliar do templo, o mesmo jovem que, ao espirrar enquanto escorava o nariz de Naigu, deixara-o cair na sopa:

\footnotetext{
Certo dia, escutando um latido estridente, Naigu saiu para averiguação. O jovem brandia um pedaço de madeira de aproximadamente sessenta centímetros, no encalço de um cachorrinho vira-lata magro magro. Mas não ficava apenas nisso. Ele cercava o cão no compasso da sentença: "Não consigo acertar o nariz! Toma! Toma! Ah, não consigo acertar o nariz!" Misantropo, Naigu arrancou o pedaço de madeira das mãos do menino e acertou-o com toda a força em sua cabeça.

$\mathrm{O}$ pedaço de madeira? Era a tabuinha que, num tempo não muito remoto, erguera o nariz do velho monge. (AKUTAGAWA, 2003, p. 32-3).
}

Esta cena é especialmente significativa, pois indica uma possibilidade de interpretação alegórica para a narrativa: o "cachorrinho vira lata magro magro", sendo judiado pelo jovem auxiliar do templo, corresponde ao estado moral deplorável do próprio protagonista, vítima da risada alheia. Do mesmo modo, podemos estender a interpretação alegórica para os demais elementos da narrativa, o que anularia o efeito fantástico, de acordo com Todorov, mas nos ajudaria a compreender melhor o tipo de humor que se apresenta aqui. 
De modo mais claro, queremos dizer que o nariz representa a causa aparente do sofrimento de Naigu, sendo que a causa verdadeira é a preocupação que ele tem com a reação da sociedade ao tamanho do seu nariz. É por isso que a transformação externa não resolve o problema; e o conto termina com a ilusão do protagonista, que ainda não compreendeu a verdadeira origem do seu sofrimento.

É preciso lembrar que o conto de Akutagawa se baseia principalmente num episódio do Konjaku Monogatari, conjunto de narrativas da tradição popular japonesa do período Heian (794-1185). Quanto ao tratamento psicológico, segundo o crítico coreano Beongcheon Yu (1976), foi inspirado no conto de mesmo nome de Gógol:

\begin{abstract}
No entanto, a história de Akutagawa não mantém nada da narrativa cruamente simples e do humor grosseiro da anedota original; nem ecoa a bizarra deformação e a risada sarcástica do escritor russo. Sóbria e séria, como disse Sôseki, o tom é irônico, e este senso de ironia deriva do ponto de vista do autor, a incerteza do ser humano por existir num mundo inconstante. A história gira em torno da própria atitude do autor que não condena nem aceita. Focando no nariz, Akutagawa opõe seu protagonista contra o mundo e mostra que nenhum lado se sobrepõe ao outro definitivamente. Enquanto a sua inteligência perspicaz não deixa escapar nem a mais leve sombra da tensão psicológica, seu senso de humor sutil contempla a fragilidade humana com uma piedade serena. (YU, 1976, p. 29 - tradução nossa) ${ }^{3}$.
\end{abstract}

Assim, o sentido religioso que costuma se apresentar de modo mais simples nas narrativas tradicionais do Konjaku Monogatari, aparece aqui ironicamente, a partir de um contraexemplo. Pois, como observamos, Naigu não aprende com a experiência, mas continua iludido com a ideia de que a sua felicidade dependa da reação positiva que os demais terão, com a volta do seu nariz ao tamanho original. Para Fengjuan Wu (2017), o cerne do problema, no caso de Naigu, "reside no fato de que não há um verdadeiro eu de acordo com a sabedoria budista, e não foi formado um processo de autoestima correto. Toda a sua felicidade é dominada pela atitude alheia" (WU, 2017, p. 301 - tradução nossa) ${ }^{4}$.

Compreendemos, portanto, que Natsume tenha considerado a narrativa de Akutagawa "sóbria e séria", pensando sobre o quanto a atitude de Naigu e dos demais personagens do conto refletem a nossa própria realidade.

\footnotetext{
${ }^{3}$ No original: "Yet Akutagawa's story retains nothing of the crudely simple narration and earthy humor of the original anecdote; nor does it echo the bizarre twist and sardonic laughter of the Russian writer. Sober and serious, as Sôseki said, the tone is ironic, and this sense of irony derives from the author's angle of vision, the uncertainty of being human in a fickle world. The story revolves the very attitude of the author who neither condemns nor condones. Using the human nose as a focal point Akutagawa pits his protagonist against the world and shows that neither side wins or loses completely. While his clear-eyed intelligence does not miss the slightest shade of psychological tension, his subtle comic sense contemplates human frailty with serene pity".

${ }^{4}$ No original: "The crux of the problem lies in the fact that there is no real self in the Buddhist wisdom, and a correct self evaluation system is not formed. All his happiness is dominated by the attitude of others"
} 
No entanto, cabe perguntar agora: de que modo a narrativa em questão pode ser considerada "sóbria e séria", ao mesmo tempo em que se elogia o "senso de humor sutil" de seu autor?

Ora, levando em conta o ridículo da situação em que se vê o protagonista, combinado à "tensão psicológica" de que nos fala Yu, na citação acima, chegamos a uma concepção de humor semelhante ao "sentimento do contrário", de que nos fala Luigi Pirandello (1996).

Assim, à primeira vista, o monge budista preocupado com seu nariz de linguiça pode nos fazer rir, pois ele representa o contrário do que se espera de um homem espiritualmente elevado. Mas, na medida em que o narrador nos revela o sofrimento íntimo do protagonista, já não podemos rir tão tranquilamente:

\begin{abstract}
Naigu era obcecado pelo nariz alheio. O templo de Ikeno'o era palco de diversas atividades. [...] Por tudo isso, a entrada e a saída de pessoas - sacerdotes, monges, samurais, civis - eram intensas. E Naigu fazia uma pesquisa minuciosa no rosto de cada uma delas. Se encontrasse alguém com nariz semelhante ao seu, já se sentiria tranquilo. Aos seus olhos não existiam os trajes azul-marinhos habituais da gente da comunidade. Tampouco os quimonos de tecido fino e de cor branca, feitos de cânhamo ou de seda. Muito menos os chapéus dourados, com matizes de vermelho utilizados pelos monges. Nem se fale dos hábitos castanhos, tingidos com faia aromática, comuns aos bonzos! Estava familiarizado com todos, eram todos imperceptíveis. Naigu não via a pessoa. Naigu via o nariz. Apenas o nariz. Mas, embora houvesse narizes curvos e narizes aquilinos, um nariz como o seu até então não fora descoberto. As tentativas se multiplicavam, e se multiplicavam os fracassos, confrangendo cada vez mais seu coração. Certa ocasião, Naigu estava a conversar com alguém e mexeu na ponta do nariz, como faria qualquer um de nós. Dessa vez, porém, enrubesceu sem motivo, feito criança, esquecendo todo o discernimento que os anos lhe trouxeram. Foi nesse exato momento que seu desconforto manifestou-se de forma imperativa. (AKUTAGAWA, 2003, p. 27).
\end{abstract}

A obsessão do protagonista pelo seu problema é tanta que ele é incapaz de perceber a realidade à sua volta: "Estava familiarizado com todos, eram todos imperceptíveis. Naigu não via a pessoa. Naigu via o nariz. Apenas o nariz" (AKUTAGAWA, 2003, p. 27). Ele é um verdadeiro escravo do seu sofrimento. E então, ao sentimos compaixão de Naigu, ao mesmo tempo em que rimos dele, não estamos mais diante da comicidade, mas sim do humorismo, conforme a definição de Pirandello.

Assim, embora este conto não se enquadre perfeitamente em nenhuma das categorias estéticas que escolhemos para analisá-lo (o fantástico, o grotesco, o cômico), a partir delas, pudemos descrever melhor as características da narrativa estudada, até chegarmos à interpretação que nos pareceu a mais adequada. E também acreditamos ter demonstrado, através de nossa análise, como o conto em questão é bem mais complexo e rico do que pode parecer inicialmente. 


\section{Da crítica à teoria}

Em nosso trabalho, priorizamos até agora a reflexão crítica, em detrimento da teórica, ou seja, o objetivo maior foi o de analisar e interpretar um texto literário específico, mais do que discutir as características gerais que se apresentam no conjunto de obras que compreendemos como sendo expressões do fantástico, do grotesco ou do cômico.

Mas, embora o nosso intuito não seja o de propor novas formulações para os conceitos teóricos acima, a nossa própria atitude, durante a análise, acabou nos conduzindo para um posicionamento diante de uma questão crucial para os estudos sobre o fantástico. Em outras palavras, nossa análise nos levou à constatação de que compreender o fantástico como "modo" e não como "gênero" nos permite englobar um conjunto muito mais amplo de obras artísticas em nosso campo de pesquisa.

Assim, os acontecimentos principais do conto de Akutagawa - o tamanho exagerado do nariz de Naigu, sua diminuição e sua volta ao tamanho original -, embora não permitam uma classificação clara no domínio do sobrenatural, são certamente parte daquilo que Filipe Furtado denominou de "metaempírico", pelo seu caráter insólito e por se manterem sem explicação (FURTADO, 2009, s/n).

Além disso, seguindo o raciocínio de Furtado, a reação perante o metaempírico nas obras não se limita apenas à hesitação ou não diante do caráter aparentemente sobrenatural do acontecimento extraordinário, mas corresponde a um "espectro", que, no caso da narrativa analisada, envolve o problema de autoestima do protagonista e o riso alheio, assim como o “sentimento do contrário" experimentado pelo leitor.

Por fim, é preciso observar que a nossa interpretação alegórica não se pretende absoluta, mas apenas mais uma dentre as possíveis maneiras de compreender a obra lida, o que significa dizer que ela não necessariamente anula o efeito fantástico - entendido agora não como a hesitação de Todorov ou a ameaça de Roas, mas como o metaempírico de Gama-Khalil:

\footnotetext{
Sem explicação, pelo metaempírico, a literatura fantástica se abre como uma fantasia que projeta enigmas, os quais clamam não por uma decifração, porém por decifrações, porque a ordem dessa literatura é a da abertura, da falta de limites não só de evocar o que não existe no solo que pisamos, mas também de abrir-se como um cristal para suscitar outros tons para enxergarmos o real. (GAMA-KHALIL, 2013, p. 30).
}

Posto isso, esperamos, com este trabalho, ter contribuído para os estudos gerais sobre o fantástico, em sua relação com o humorístico, bem como ter despertado o interesse dos leitores para a obra de Ryûnosuke Akutagawa, ainda relativamente pouco conhecida no Brasil. 


\section{Referências}

AKUTAGAWA, Ryûnosuke. Contos fantásticos. São Paulo: Editora Z, 2003.

ARÊAS, Vilma. Iniciação à comédia. Rio de Janeiro: Zahar, 1990.

ARISTÓTELES; HORÁCIO; LONGINO. A poética clássica. São Paulo: Cultrix, 1995.

BAKHTIN, Mikhail. A cultura popular na Idade Média e no Renascimento. São Paulo: Brasília: Hucitec, Edunb, 1993.

FURTADO, Filipe. "Fantástico (modo)". E-dicionário de termos literários (EDTL), coord. de Carlos Ceia, ISBN: 989-20-088-9. Disponível em: http://www.edtl.com.pt. Acesso em: 22 abr. 2021.

GAMA-KHALIL, Marisa Martin. “A literatura fantástica: gênero ou modo?”. Terra roxa e outras terras: Revista de estudos literários. Londrina: UEL. Disponível em: http://www.uel.br/pos/letras/terraroxa/g pdf/vol26/TR26b.pdf. Acesso em: 22 abr. 2021.

GÓGOL, Nicolai. O nariz. In: CALVINO, Italo (org.). Contos fantásticos do século XIX. São Paulo: Companhia das Letras, 2004.

KAUPATEZ, Digo. "Posfácio”. In: AKUTAGAWA, Ryûnosuke. Contos fantásticos. São Paulo: Editora Z, 2003.

KAYSER, Wolfgang. O grotesco: configuração na literatura e na pintura. São Paulo: Perspectiva, 1986.

LIPPIT, Noriko Mizuta. "From tale to short story: Akutagawa's Toshishun and It's Chinese Origins". In: Reality and Fiction in Modern Japanese Literature. M. E. Sharpe Inc., 1980, pp. 39-54. Disponível em: https://www.enotes.com/topics/akutagawa-ryunosuke/criticalessays/criticism. Acesso em: 09 fev. 2021.

MAUPASSANT, Guy de. "O Horla". In: MAUPASSANT, Guy de. O Horla e outras histórias. Porto Alegre: L\&PM, 1986.

PIRANDELLO, Luigi. O humorismo. São Paulo: Experimento, 1996.

ROAS, David. A ameaça do fantástico: aproximações teóricas. São Paulo: Unesp, 2014.

TODOROV, Tzvetan. Introdução à literatura fantástica. São Paulo: Perspectiva, 2003.

WU, Fengjuan. "Research on personalities of characters in Ryûnosuke Akutagawa's early works". In: Proceedings of the 2017 International Conference on Culture, Education and Financial Development of Modern Society. Disponível em: https://www.atlantispress.com/proceedings/iccese-17/25875316. Acesso em: 10 fev. 2021.

YU, Beongcheon. "The flight to Paranassus". In: AKUTAGAWA: an introduction. Wayne State University Press, 1972, pp. 15-42. Disponível em: https://www.enotes.com/topics/akutagawaryunosuke/critical-essays/criticism. Acesso em: 09 fev. 2021. 